\title{
AMOR SUPERA CONFLITOS ENTRE FILHOS E MÃES - A CONSTRUÇÃO DISCURSIVA DO ISLÃ COMO RELIGIÃO DO ATRITO
}

\author{
LOVE OVERCOMES CONFLICTS BETWEEN CHILDREN AND \\ MOTHERS - THE DISCURSIVE CONSTRUCTION OF ISLAM AS THE \\ RELIGION OF TROUBLE
}

Daniele dos Santos de Souza'

Fernando Zolin-Vesz ${ }^{2}$

Adriana Auxiliadora da Silva ${ }^{3}$

\begin{abstract}
RESUMO: Este artigo analisa a reportagem "Amor supera conflitos entre filhos e máes", publicada na ediçâo n. 9.208, de 14 de maio de 2017, no jornal A Gazeta, a qual veicula três diferentes histórias de conflito entre máes e filhos, com ênfase no relato sobre uma jovem convertida ao Islá. Entende-se que tal reportagem năo apenas (re)produz sentidos sobre o amor materno, hábil a diluir contendas, inclusive a conversáo da filha a uma religiăo construída discursivamente como conflituosa, bem como retoma enunciados que constroem discursivamente o Islă como religiâo do atrito. A (re)produçâo desses enunciados, que atrelam o Islá ao espaço do embate, parece produzir determinados efeitos de verdade sobre como essa prática religiosa é percebida no Brasil contemporâneo.
\end{abstract}

PALAVRAS-CHAVE: Amor materno. Islā. Conflito.

ABSTRACT: This article analyzes the report "Amor supera conflitos entre filhos e mâes" (in English, "love overcomes conflicts between children and mothers"), published in the edition n. 9.208, on May 14, 2017, at A Gazeta newspaper. The mentioned material reports three different stories of conflict between mothers and children, emphasizing the report of a young Muslim-converted woman. It is understood that this report not only (re)produces meanings about maternal love, capable of diluting disputes, including the conversion of a daughter to a religion constructed discursively as a troublemaker, but also takes up statements that discursively construct Islam as the religion of conflicts. The (re) production of those statements that link Islam to the space of the clash seems to produce meaningful effects on how this religious practice is perceived in contemporary Brazil.

KEYWORDS: Maternal love. Islam. Conflict.

1 UFMT, Cuiabá-MT, Mestre em Estudos de Linguagem, técnica em assuntos educacionais da Faculdade de Comunicaçăo e Artes (FCA).E-mail: daniele.souza@outlook.com

2 UFMT, Cuiabá-MT, Doutor em Letras e Linguística, professor do Departamento de Letras e do Programa de Pòs-Graduaçăo em Estudos de Linguagem (PPGEL).E-mail: fernando_vesz@hotmail.com

3 UFMT, Cuiabá-MT, Mestre em Estudos de Linguagem, professora da Secretaria de Estado de Educaçáo de Mato Grosso (SEDUC-MT).E-mail: profadrianacefapro@gmail.com 


\section{CONSIDERAÇÕES INICIAIS}

No Brasil, o segundo domingo de maio é uma data que centraliza discursos acerca da identidade da mulher que assume o papel de máe, os quais sâo veiculados nos diferentes espaços de informaçăo e retomam enunciados a fim de definir sentidos para a maternidade. Expressôes como "ser măe é padecer no paraíso" parecem remeter à definiçâo da maternidade atrelada a uma concepçăo generalizada e naturalizada de que ser mâe é amar de maneira indefectível. Para além de mero sentimento, o amor materno parece ser concebido discursivamente como uma construçáo ativa, resistente o suficiente para superar as adversidades, como as discordâncias entre máes e filhos, ou ainda as implicaçōes sociais que tais divergências podem ocasionar. Reforça-se a um só tempo o que é um desafio - o padecimento - e o que é ser măe, aquela cujo amor tudo supera.

Nessa seara, analisamos neste artigo a reportagem "Amor supera conflitos entre filhos e máes", escrita por Ana Flávia Corrêa e publicada em 14 de maio de 2017, Dia das Máes daquele ano, à página 3E do caderno dominical Zine da ediçăo n. 9.208 do jornal A Gazeta, que circula pelo Estado de Mato Grosso. A reportagem enfatiza três histórias que evidenciam o amor materno diante de determinados embates: a identidade de gênero de um homem transgênero, o namoro que atrapalha os estudos da filha e uma jovem que se converte ao Islă. A história que ganha destaque, tanto na manchete estampada na capa da ediçáo do jornal quanto na reportagem em si, por meio da foto de um dos três jovens que reportam suas histórias de prevalência do amor materno, é a da jovem convertida ao Islâ. Apesar de a matéria também apresentar a imagem de um homem transgênero, rodeado pela família, tanto na capa quanto na reportagem, o tamanho da foto da jovem muçulmana é maior em ambos os casos. Sendo assim, notamos que tal produçăo jornalística veicula sentidos náo somente sobre o que é ser máe, mas também retoma e reforça concepçôes sobre o Islă. Diante da combinaçăo entre a religiâo islâmica e o conflito, construída discursivamente pela reportagem, buscamos compreender de que maneira tal enlace (re)produz sentidos sobre o Islá como a religiáo desordeira do mundo contemporâneo.

Portanto, para a análise proposta, lançamos máo dos conceitos foucaultianos de discurso, verdade e poder, de modo a compreender as circunstâncias que permitem e criam condiçóes para a percepçăo do Islă como uma religiăo de conflito, produzindo efeitos de verdade e poder sobre tal entidade. Tal estudo do discurso nâo se centra na análise da materialidade linguística, dado que nâo constitui o eixo analítico central, pois o conceito de discurso, para Foucault (2008), relaciona-se com a produçâo de enunciados que contribuem para a construçấo de determinados sentidos em certo momento sócio-histórico e năo está centrado na relaçâo direta com a língua (MAINGUEANEAU, 2015). Assim, buscamos compreender as condiçōes que permitem o surgimento de determinados enunciados em relaçấo a tal religiấo, e nâo outros em seu lugar, de modo a correlacionar tal reportagem a determinada formaçáo discursiva (FOUCAULT, 2008). Se, na perspectiva foucaultiana de discurso, o enunciado nâo se define apenas como um conjunto de signos ou unidades possíveis linguisticamente, como uma frase, por exemplo, mas como uma prática que atribui sentidos a partir de uma regularidade intrínseca, enfatizamos, dessa forma, enunciados da reportagem que buscam construir a compreensáo proposta acima (particularmente, a imagem e a manchete constantes na 
capa do jornal; a imagem e o título da reportagem; e um excerto da própria reportagem). Como observa Foucault (2012), o regime de verdade é próprio de cada sociedade, a qual permite a circulaçáo de determinados discursos como verdadeiros, além de definir o que distingue os verdadeiros dos falsos. Consideramos que os efeitos de verdade que relacionam o Islá ao conflito, tal qual a reportagem analisada parece veicular, estâo corporificadas na linguagem, visto que, ao referir-se ao Islá, há uma recorrência nâo ao que de fato possa ser, mas ao campo de associaçôes, conotaçóes e significados que circunda tal palavra. Associá-lo à contenda em produçăo textual sobre o Dia das Măes pode năo ser inócuo tampouco insólito, uma vez que invoca uma formaçâo discursiva cujas condiçóes de existência e durabilidade se fortalecem à medida que se legitimam verdades sobre o mesmo.

Em última análise, entendemos que a associaçáo da religiăo islâmica como uma entidade conflituosa retoma enunciados orientalistas (SAID, 2016) que colocam em movimento o antagonismo do Islă, visto historicamente, no mundo ocidental, como um oposto binário à ortodoxia judaico-cristă (PINTO, 2014; SAID, 2016). Tal construçáo ganhou novos contornos após os eventos que sucederam o 11 de setembro (DABASHI, 2017). Nesse feitio, por meio deste estudo, buscamos entender de que maneira as práticas linguísticas ainda podem manter colonialidades fundamentadas em oposiçóes binárias como Ocidente/Oriente, conflito/harmonia, opressăo/liberdade, e quais os efeitos de verdade ainda produzem na contemporaneidade.

\section{ISLÃ: UMA ALTERIDADE RADICAL CONSTRUÍDA DISCURSIVAMENTE}

Comumente construída cultural e politicamente pelas sociedades ocidentais como uma religiăo de fanáticos radicais, opressores, irracionais e tradicionais, o Islă é constituído como um oposto binário ao que se relaciona ao mundo ocidental, o qual se define como livre, racional, tolerante e moderno (PINTO, 2014). A construçăo discursiva que o concebe como uma alteridade radical năo é algo que irrompe no tempo sem precedentes; antes, uma rede de interesses que é convocada ao discuti-lo, caracterizá-lo, colocá-lo em açâo a partir de uma regularidade capaz de dotar de força e durabilidade os enunciados a ele relacionados. Podemos depreender de Said (2016) que a regularidade mencionada se refere ao orientalismo, o qual, no entendimento do autor, permitiu que o Oriente e o que estivesse a ele relacionado, como o Islâ, fossem produzidos política, ideológica, militar, sociológica, científica e imaginativamente em oposiçăo ao Ocidente.

Ainda que nas últimas duas décadas, em decorrência do 11 de setembro e demais acontecimentos no Oriente Médio, o Islă tenha aparecido com certa frequência nas produçóes midiáticas, as condiçôes que permitem que a ele sejam relacionados diferentes tipos de violência se tornam possíveis em decorrência de como tal religiáo foi construída discursivamente pelo pensamento orientalista dentro de determinado regime de verdade. Para Foucault (2012), é o regime de verdade, o qual é próprio de cada sociedade, quem integra e coloca em funcionamento determinados discursos ou saberes como verdadeiros. Cumpre ressaltar que náo é o intuito deste estudo o alcance do que seria de fato verdadeiro ou falso sobre o islá, mas verificar de que maneira foi construído como uma alteridade 
radical e os efeitos de sentido mobilizados e percebidos na reportagem aqui analisada. Em outras palavras, năo se trata da discussâo se a religiâo islâmica é ou náo opressora com as mulheres, pois, em uma perspectiva que ultrapassa o pensamento binário do bem e do mal, entendemos que visóes de mundo estruturadas em dicotomias sâo capazes de relegar as pluralidades tanto do Ocidente quanto do Oriente. Este năo é só opressor, aquele năo é só livre, há questōes complexas que já năo podem ser ignoradas na contemporaneidade.

O pensamento orientalista concentra-se em um teor essencialista e que torna homogêneo o oriental, como se houvesse apenas uma cultura, um fenótipo, uma religiăo e uma visăo de mundo, de maneira a contrastá-lo de forma tăo distinta do ocidental que as similaridades parecem năo existir (PINTO, 2014; SAID, 2016; SOUZA; ZOLIN-VESZ, 2018). A essencializaçâo ocorre também com o Islâ, que é retratado, por meio de generalizaçôes, como uma doutrina que preconiza o fanatismo e a violência. A esse respeito, Demant (2015) argumenta que a religiâo islâmica năo predispóe seus seguidores ao fanatismo e à violência, o que suscita o seguinte questionamento: por quais razôes os muçulmanos sâo apresentados nos discursos midiáticos como terroristas e perigosos? Para o autor, as mídias veiculam o que é comercialmente rentável para suas empresas, muitas vezes sem a preocupaçâo a respeito dos sentidos provocados por tal veiculaçâo. Há a dispersăo de notícias que mostram muçulmanos envolvidos em ataques terroristas, sequestros, situaçôes de opressáo contra mulheres, mas, por outro lado, năo se observa, de acordo com Demant (2015), a difusáo de matérias jornalísticas que publiquem na mesma intensidade a construçâo e inauguraçăo de uma mesquita, por exemplo. Portanto, ao veicular algumas "verdades" sobre o Islá, outras sáo relegadas a um espaço de menor circulaçăo no mundo ocidental, o que explica o fato de ainda hoje a religiăo muçulmana ser tâo pouco conhecida em sua diversidade de práticas, vivências, formas de interpretá-la ou ainda em sua pluralidade geográfica, étnica e cultural (PINTO, 2014). Além disso, sendo o Islā desenhado como uma alteridade radical e oposta à ortodoxia judaico-cristă, a dispersăo de enunciados que o constroem discursivamente também produz sentidos sobre a religiosidade cristă ocidental. Ao indicar a religiâo islâmica como intolerante e violenta, o seu polo oposto é indicado como tolerante e pacífico. No entanto, conforme destaca Demant (2015), religiǒes, como o Cristianismo, náo foram menos envolvidas em situaçăo de violência e intolerância. Por exemplo, a inquisiçấo é relembrada por Pinto (2014) como um ponto frequentemente esquecido na narrativa sobre o Ocidente.

Analisar as condiçôes as quais permitiram, na contemporaneidade, que o Islá fosse construído como uma instituiçâo correlata ao fanatismo, ao terrorismo e avessa à modernidade ocidental perpassa pelo entendimento de como e por quem tal entidade foi representada. Na tessitura de Said (2016), entende-se que o orientalismo permitiu que o Oriente fosse representado (e dominado) pelo Ocidente, visto que, ao fazer circular determinadas verdades, foi possível manejar, teorizar, representar e dominar o mundo oriental. $O$ autor justifica o medo europeu em relaçấo ao muçulmano ao situá-lo historicamente na grande expansâo da hegemonia militar, cultural e religiosa do Islă em 632, após a morte de Maomé. Os exércitos muçulmanos ocuparam a Pérsia, a Síria, o Egito, a Turquia e 
a África do Norte, conquistando também, no século VIII, a Península Ibérica, além de estender seu domínio até a Índia, a Indonésia e a China, por volta dos séculos XII e XIV. Para a Europa cristá, o Islá simbolizava um trauma marcado pelo terror, pela barbárie, o oposto extremo do próprio Cristianismo. A compreensăo de que o Islă e o Cristianismo ocupam polos opostos, sem similitudes, é exemplificada por Said (2016) pela maneira análoga com que Maomé foi descrito pelos pensadores cristăos: supunha-se que Maomé seria a base do credo muçulmano assim como Cristo era o alicerce do Cristianismo. Segundo o autor, é a partir desse equívoco que emergem os enunciados que apontam Maomé como impostor, o disseminador de uma falsa Revelaçăo, um apóstata e herege.

O temor ocidental também se fortaleceu e ressurgiu com força pós-11 de setembro de 2001, quando os Estados Unidos sofreram ataques em seu território. Conforme Foucault (2012), os acontecimentos discursivos estáo abertos à repetiçấo, à transformaçấo, à reativaçăo e estâo interligados àqueles que os antecedem. A Guerra ao Terror, declarada pelo presidente norte-americano George W. Bush, após a queda das Torres Gêmeas, produzia sentidos que atingiam também as representaçóes sobre o Oriente: antes longínquo e inerte, os sucessivos ataques ao território dos Estados Unidos e a alguns países da Europa mostraram que a direçâo das armas poderia ser alterada (DABASHI, 2017). Em relaçâo ao Brasil, mesmo após quase duas décadas desde a queda das Torres Gêmeas, ainda há relatos de hostilidade sofridos por muçulmanos (SOUZA; ZOLIN-VESZ, 2018), decorrente da ótica orientalista sobre o Islá reforçada pelo 11 de setembro.

\section{QUANDO 0 AMOR SUPERA CONFLITOS ENTRE FILHOS E MÃES...}

Nesta seçâo, analisamos imagens e excertos da reportagem "Amor supera conflitos entre filhos e măes", apresentados na ordem em que estăo distribuídos no jornal A Gazeta, de 14 de maio de 2017 - em particular, a imagem e a manchete constantes na capa do jornal, a imagem e o título da reportagem, e um excerto da própria reportagem.

A capa de um jornal é o primeiro item com o qual o leitor tem contato. Conforme Lima e di Fanti (2010), os fatos presentes na capa săo, via de regra, aqueles que costumam ocupar espaço privilegiado nas páginas internas, além de corresponderem a um apelo principalmente mercadológico: os fatos ali estampados precisam atender ao interesse do maior número de pessoas para, assim, o jornal se tornar atrativo o suficiente para ser comercializado. Posto isso, examinemos a Figura 1 que estampa o primeiro momento em que a reportagem aqui selecionada é apresentada ao leitor na capa do jornal. 


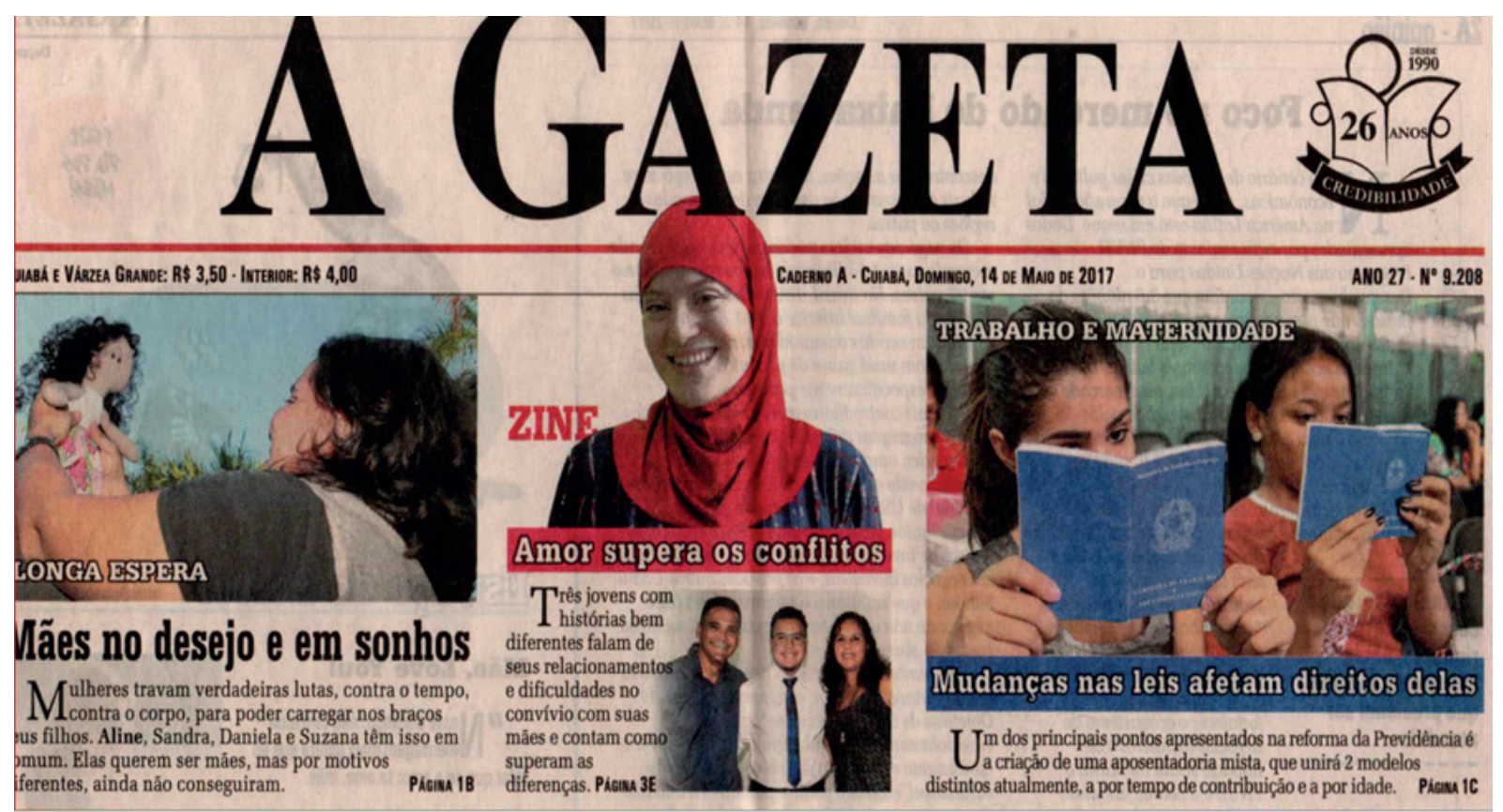

Figura 1 Topo da capa do jornal A Gazeta, de 14/5/2017

O recorte acima evidencia a manchete "Amor supera os conflitos", ilustrada por meio da foto de uma jovem mulher trajando um véu vermelho, conhecido como hijab ou véu islâmico. A combinaçâo da foto com o recurso visual da própria manchete contribui para evidenciar o destaque que a história de conflito entre a mâe e a filha convertida ao Islâ recebe, uma vez que a figura de um jovem ladeado por dois adultos surge logo abaixo em tamanho menor. Portanto, o destaque à reportagem "Amor supera os conflitos" parece evidente, bem como os personagens que a compóem, tendo em vista a posiçâo ocupada na capa do jornal: no topo, centralizada, ao lado de outras duas reportagens e imagens nas quais nâo é possível individualizar as pessoas, cujos rostos năo estâo totalmente visíveis. A reportagem integra o caderno dominical Zine, o qual também aparece escrito na cor vermelha. A eleiçâo da cor vermelha pode ser entendida tanto relacionada ao emprego do vocábulo "amor", que abre o título da reportagem, quanto ao efeito de busca por singularidade entre os vários elementos visuais que compōem o todo da página, pois, como observam Lima e di Fanti (2010), constitui um matiz de cor que pode realçar e chamar a atençâo do leitor. Tal eleiçâo parece-nos produzir, portanto, um efeito de unidade e, principalmente, de relevância da referida matéria frente às demais que a acompanham. Por esse ângulo, importante notar também o texto que compóe a manchete:

\section{Excerto 1}

\section{Amor supera os conflitos}

Três jovens com histórias bem diferentes falam de seus relacionamentos e dificuldades no convívio com suas măes e contam como superam as diferenças. (CORRÊA, 2017, p. 3E) 
Embora anuncie que se trata de três histórias sobre as dificuldades e a superaçăo das diferenças no relacionamento entre măes e filhos, é a imagem de uma jovem vestindo o véu islâmico que sobressai na capa do jornal, como descrevemos acima. A nosso ver, tal disposiçăo, acompanhada pelo texto, pode contribuir para a (re)produçăo de determinados efeitos de verdade sobre o Islá, visto que a presença do véu parece ser determinante para a associaçăo com o Islá. O emprego de vocábulos, como "conflitos", "dificuldades" e "diferenças", associados à imagem de uma mulher trajando o hijab, coopera para retomar enunciados orientalistas (SAID, 2016) que constroem o Islá como a religiâo do conflito. Como nâo săo inéditos, como descrevemos na seçăo anterior, podem, portanto, ser mais facilmente apreendidos pelo leitor, particularmente no que se refere à associaçâo da religiâo islâmica com uma alteridade radical, o que se exprime, por exemplo, nas vestimentas femininas tidas como avessas à modernidade do Ocidente (SAID, 2016). Assim, a relaçâo entre conflito e Islă parece se consolidar já na capa do jornal. Tal relaçáo parece ser ampliada na reportagem, constante no caderno dominical Zine daquela ediçăo do jornal A Gazeta.

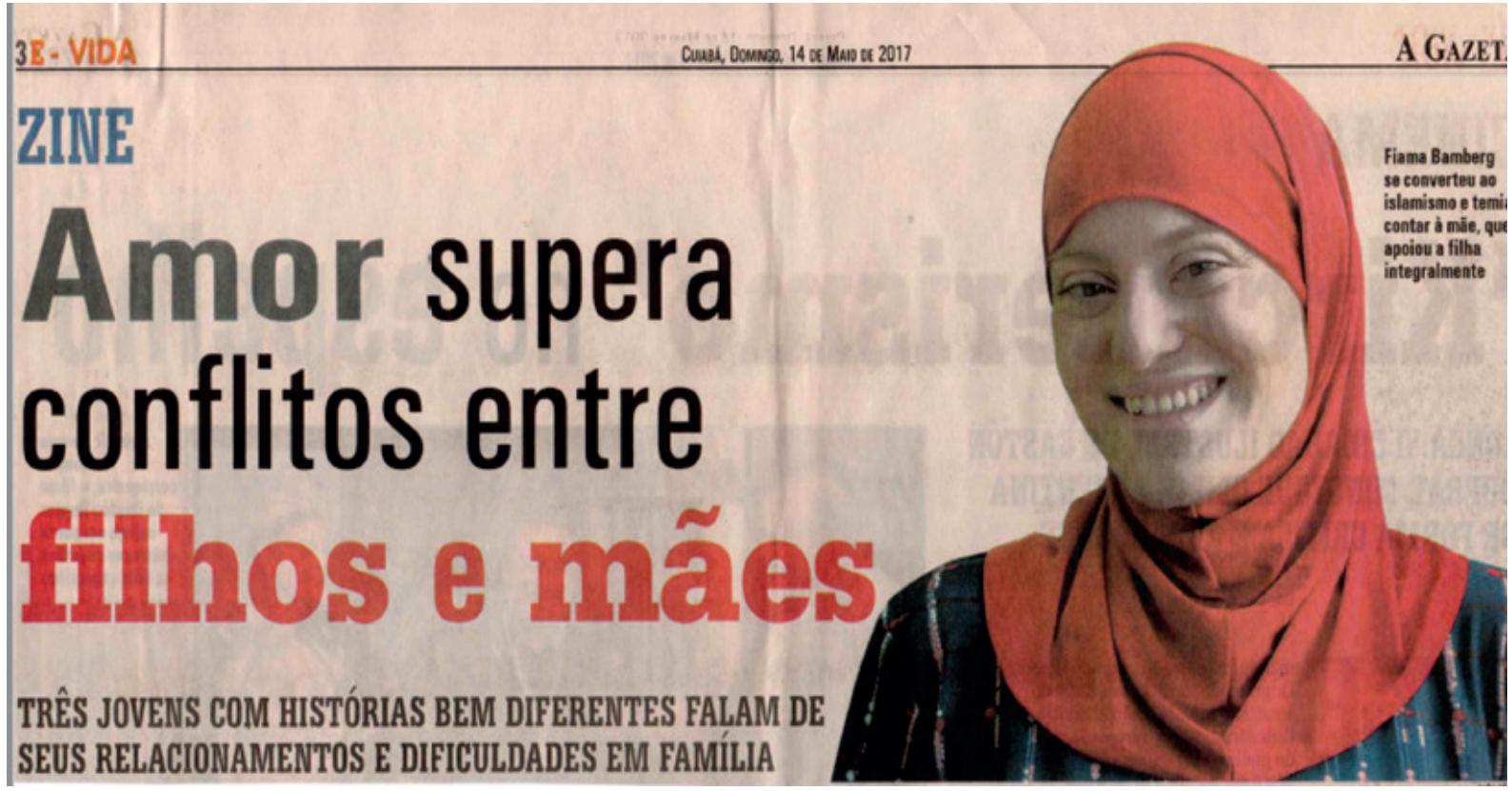

Figura 2 Topo da reportagem

A reportagem estampa novamente a foto da jovem muçulmana, em tamanho ampliado em comparaçăo com a imagem constante na capa, uma vez mais ilustrando o título e o subtítulo da reportagem que evidenciam histórias de conflito (e superaçăo) no relacionamento entre máes e filhos. Dessa vez, entretanto, a fotografia da jovem é acompanhada pela legenda "Fiama Bamberg se converteu ao islamismo e temia contar à mâe, que apoiou a filha integralmente", o que nos parece enfatizar a relaçâo de conflito destacado pela reportagem. A conversăo ao Islă em um país cultural e religiosamente construído como cristăo é evidenciada pela reportagem como algo conflituoso, capaz de interferir na relaçăo entre măes e filhos ao ponto de a filha temer algum tipo de 
represália ou afastamento da mâe. Badinter (1985) aponta de que maneira a figura materna é construída no pensamento ocidental ao longo dos séculos, de modo a se tornar, especialmente após o século XVIII, aquela cuja competência é formar, dentro do seio familiar, o que se considerava um bom cristăo. O temor da jovem parece retomar de maneira múltipla as práticas discursivas que constroem o papel materno, visto que tal temor referencia a necessidade do aval daquela cujo papel é produzido historicamente como responsável pela formaçâo do bom cristăo. Além disso, o temor relaciona-se a uma possível irregularidade (de um bom cristăo) que parece ser a conversâo a uma religiăo supostamente tăo diferente da doutrina religiosa ocidental. $\mathrm{O}$ apoio integral da mâe, conforme relatado na legenda da foto, é destacado como uma autorizaçăo, a superaçăo de um conflito que só se consuma por meio do amor materno - e năo do entendimento de que tal denominaçăo religiosa pode năo ser sinônimo de contenda, concretizado pelos construtos orientalistas sobre o Islá.

O destaque dado à história da jovem muçulmana, portanto, coloca em embate os diferentes sentidos atribuídos pela reportagem à palavra "conflito": dentre três histórias que relatam situaçōes conflituosas, é a figura de uma mulher trajando o véu islâmico que ocupa uma posiçấo privilegiada e de apelo comercial desde a capa do jornal. A conversáo voluntária de uma mulher jovem ao Islá parece colocar em embate sentidos que relacionam o uso do véu à submissâo, em oposiçâo à liberdade feminina, algo tăo caro à civilizaçăo ocidental. O uso do véu por mulheres muçulmanas, principalmente após o 11 de setembro, ganhou "um reforço simbólico no sentido de metonímia máxima e incontestável de opressâo" (BASTOS, 2016, p. 27). Para Abu-Lughod (2012), a mobilizaçấo da figura feminina muçulmana está intimamente relacionada à retórica do salvamento: a mulher muçulmana se tornou aquela que precisava ser salva, pela sociedade ocidental, de homens árabe-muçulmanos apontados como inimigos da liberdade. Desse modo, sendo o Islă o espaço da opressăo e da submissăo, é cognoscível o destaque da reportagem à história jovem muçulmana (em comparaçâo com as demais personagens), bem como a apresentaçâo de sua conversâo como uma "história bem diferente" associada a "dificuldades em família", já que, ainda que tenha se convertido voluntariamente, náo parece ser conciliável a possibilidade de uma mulher opcionalmente resignar-se a um espaço construído discursivamente como opressor.

Contudo, a conversáo da jovem muçulmana pode ser percebida como um ato de rebeldia, observada pela reportagem desde a adolescência de Fiama Bamberg, contra a qual somente algo maior pode redimir tamanha insubordinaçáo à norma vigente - o amor materno.

\section{Excerto 2}

A filha costumava fugir das aulas monótonas para acompanhar o ensaio de uma banda de garagem e adorava trocar a cor do cabelo, cada dia com uma pigmentaçăo diferente. Nessa época, a estudante também começou a fumar e as brigas só se intensificaram. "Os principais conflitos que eu tive com minha măe foram por năo ouvi-la na adolescência. Eu sempre ouvia mais os amigos do que ela", explicou. Foi em 2014, no entanto, que Fiama conheceu seu atual noivo, responsável por apresentá-la ao Islam. Quando pensou em contar para a máe sobre a nova religiăo, năo imaginou que a reaçấo seria positiva. "Eu morri de medo achando que ela ficaria 
chateada, mas foi totalmente o contrário. Ela veio para a Mesquita, quis conhecer e conversar com todo mundo. Hoje as pessoas adoram quando ela vem e ela também adora vir me visitar", afirmou. (CORRÊA, 2017, p. 3E)

Diante do relato de indisciplina e de conflitos durante a adolescência, a conversăo ao Islâ é apresentada como mais um momento de tensâo na relaçâo entre mâe e filha: "eu morri de medo achando que ela ficaria chateada...". Assim, a recente mudança de prática religiosa é colocada como uma dissidência que causa temor a uma jovem que, de acordo com a reportagem, já experimentara outras situaçōes de dissensăo com a máe. Entretanto, exacerbada agora quando a jovem opta facultativamente por uma religiâo construída discursivamente no Ocidente como conflituosa. Tornar-se adepta ao Islă é uma conversâo apresentada de maneira diferente dos relatos comumente veiculados sobre mudanças religiosas: se, muitas vezes, vemos relatos em que pessoas dizem ter suas vidas transformadas após se vincularem a determinada doutrina, o mesmo nâo parece ocorrer na reportagem analisada em que há uma centralizaçăo no entendimento do Islá como uma alteridade que causa receio até mesmo no momento de anunciar a conversāo no núcleo familiar.

Contudo, o temor da recém-convertida é mitigado pelo amor materno, aquele que tudo supera, inclusive as escolhas individuais dos filhos, ainda que tais eleiçôes sejam díspares do que se considera padrâo. O medo de ter sua seleçăo repugnada é substituído pela surpresa ao perceber que a mâe náo apenas visita a mesquita como também se apresenta disposta a conhecer as pessoas que participam da vida religiosa da filha, elementos que solidificam o enunciado que é título da matéria: o amor materno é capaz de superar os conflitos. $O$ encerramento da história da jovem muçulmana consolida, dessa forma, o devotamento e o padecimento para que alguém seja considerado uma boa mâe (BADINTER, 1985), pois, apesar das dissidências na adolescência e da conversáo ao Islá, o amor materno suplanta qualquer tipo de atrito que possa ocorrer na relaçâo entre mâes e filhos.

\section{CONSIDERAÇÕES FINAIS}

Neste artigo, analisamos a reportagem "Amor supera conflitos entre filhos e mâes", publicada na ediçâo n. 9.208, de 14 de maio de 2017, em um dos cadernos dominicais do jornal A Gazeta, no Dia das Máes daquele ano. A reportagem narra conflitos e dificuldades no relacionamento de três jovens com suas respectivas măes, com ênfase na figura de uma jovem convertida ao Islá cujo relato é apresentado como mais uma possível desavença na relaçăo com a măe - no caso da jovem, das muitas observadas desde a adolescência -, mas superada pelo amor materno. Tal conversăo sugere a produçăo, a um só tempo, de sentidos sobre o amor materno, aquele que tudo supera, e sobre o Islá, a religiăo do atrito, dos "conflitos", "dificuldades" e "diferenças", conforme apresentado já na manchete da reportagem na capa do jornal A Gazeta.

Para a compreensâo das condiçóes que permitem que o Islă seja construído como uma religiâo conflituosa, propomos como referencial teórico as relaçôes que o produzem como uma alteridade radical (SAID, 2016). Ainda que o amor materno seja apresentado como diluidor de conflitos, ou como aquele que tudo supera em prol do bom relacionamento familiar, percebemos que tal concepçấo corrobora para que o Islă seja 
retomado como uma entidade de contenda. A conversăo voluntária da jovem pode ser associada tanto à aceitaçăo à submissâo feminina supostamente reservada às mulheres muçulmanas quanto à subversăo - registrada desde a adolescência da jovem -, ao converter-se a uma religiăo construída discursivamente como radical. O amor materno supera todo e qualquer conflito, mesmo quando uma filha, rebelde desde a adolescência, decide converter-se ao Islá. Afinal, como apresentamos ainda na introduçăo, ser mâe é padecer no paraíso.

\section{REFERÊNCIAS}

ABU-LUGHOD, L. As mulheres muçulmanas precisam realmente de salvaçâo?: reflexôes antropológicas sobre o relativismo cultural e seus outros. Revista Estudos Feministas, v. 20, n. 2, p. 451-470, 2012.

BADINTER, E. Um amor conquistado: o mito do amor materno. Trad. Waltensir Dutra. Rio de Janeiro: Nova Fronteira, 1985.

BASTOS, L. M. P. C. Fetiche neo-orientalista: o problema da autorrepresentaçâo do subalterno e as autobiografias de mulheres muçulmanas. Goiânia: Editora da UFG, 2016.

CORRÊA, A. F. Amor supera conflitos entre filhos e mâes. A Gazeta, Cuiabá, 14 maio 2017, Zine, p. 3E.

DABASHI, H. Post-orientalism: knowledge and power in a time of terror. Nova York: Routledge, 2017.

DEMANT, P. O mundo muçulmano. 3. ed. Săo Paulo: Contexto, 2015.

FOUCAULT, M. A arqueologia do saber. Trad. Luiz Felipe Baeta Neves. 7. ed. Rio de Janeiro: Forense Universitária, 2008.

FOUCAULT, M. Microfísica do poder. 25. ed. Sâo Paulo: Graal, 2012.

LIMA, E.; DI FANTI, M. G. Tensionamento de vozes na primeira página do jornal: o episódio Aracruz na capa de Zero Hora. Gragoatá, v. 15, n. 28, p. 175-192, 2010.

MAingueneAU, D. Discurso e análise do discurso. Trad. Sírio Possenti. Sáo Paulo: Parábola, 2015.

PINTO, P. G. H. R. Islā: religiāo e civilizaçâo: uma abordagem antropológica. Aparecida: Santuário, 2014. 
SAID, E.W. Orientalismo: o Oriente como invençăo do Ocidente. Trad. Rosaura Eichenberg. Sâo Paulo: Companhia das Letras, 2016.

SOUZA, D. S.; ZOLIN-VESZ, F. Da hospitalidade à intolerância ao migrante árabe: construçôes discursivas sobre um mesmo Brasil. Trabalhos em Linguística Aplicada, v. 57, n. 2, p. 877-893, 2018. 